\section{New Year's Resolutions}

Every January is a fresh start. We shed the travails of the previous year (and boy, what a difficult year it was this time!) and we promise ourselves that we will be better people. We will lose weight, exercise more, clean out our closets, volunteer to help the needy, stick to our budgets (and so on and so on). This year, though, I decided to try something different. This year, my goal is to be a better oncologist.

After many years in practice, I sometimes find myself less sensitive to the needs of my patients. I don't mean to do this. And I think I remain compassionate and caring at the bedside. But I don't always focus enough on the context of their lives. Our patients are on a difficult journey far beyond the physical part, which arguably, we all are well trained to manage.

So here is what I resolve:

- To remember that I am treating a patient, not a disease. That every intake should start with an understanding of their lifestyle, their profession, their family, and their avocations. Without that context, we may not communicate as clearly as we can or understand what might be competing for their time and attention.

- To understand that, with every new consult, the patient may not yet fully grasp their condition. I will start every new conversation about the cancer by asking first what they understand about their diagnosis and the extent of their disease.

- To respect the fact that cancer can be a frightening diagnosis. In the beginning, a patient may not hear everything I explain. This is especially true for hospitalized patients, who may also be limited in comprehension because of drugs they have been given or the unsettling environment. I promise to patiently repeat necessary information when I see them again as outpatients.

- To remember that, when patients ask me about their chance of benefit and length of life gained with therapy, I will interpret statistics properly. The increase in survival for a group of patients cannot be transferred to an individual. When an individual responds to treatment, their increase in survival may be manyfold that of the group.

- To appreciate that I have a limited view of my patients' concerns. I can address the clinical part, but patients face many other distressing concerns. These can include financial strain or inability to attend to family and professional obligations. Although I may not be able to fix these things, I can at least share in their concerns and steer them to resources that may be able to help.

- To consider value in every action I take, whether ordering a test, engaging a consultant, prescribing therapy, or managing side effects.

- To accept always that there is a point when active treatment is no longer of value and that patients may well live longer with good attention to symptom management.

Well, those are my "resolutions." You may have other thoughts about how to be a better oncologist. Please send these ideas my way and I'll add them to the list. After all, there is ALWAYS room for improvement!

What do you think? Please e-mail correspondence (include contact information) to JNCCN@nccn.org.

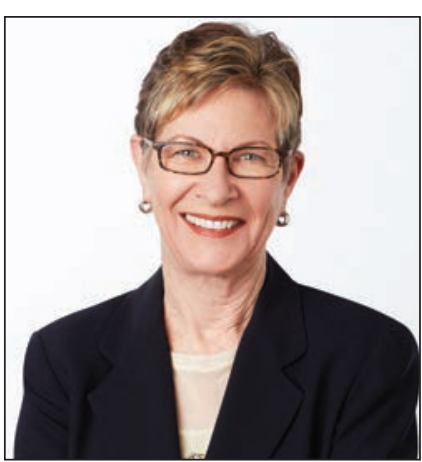

Margaret Tempero, MD

Margaret Tempero, MD, is a Professor of Medicine and Director of the UCSF Pancreas Center and editor-in-chief of JNCCN. Her research career has focused on pancreatic ductal adenocarcinoma, especially in the area of investigational therapeutics. Dr. Tempero has served on the ASCO Board of Directors and as ASCO President. She currently serves on the ASCO Conquer Cancer Foundation Board. She codirected the AACR/ASCO Methods in Clinical Cancer Research and taught this course and similar courses in Europe and Australia. She was founding Chair of the $\mathrm{NCl}$ Clinical Oncology Study Section and served as a member and Chair of the NCl Board of Scientific Counselors Subcommittee $A$. She is a member of the Scientific Steering Committee and Chair of the Clinical and Translational Study Section for the Cancer Prevention \& Research Institute of Texas. She is or has been on the Scientific Advisory Boards of the Lustgarten Foundation, the Pancreatic Cancer Action Network, the V Foundation, The Alberta Canada Cancer Board, and the EORTC. She served as a member of the Oncology Drug Advisory Committee for the FDA. She has served as Deputy Director and Interim Director for the UNMC Eppley Cancer Center. She is Chief Emeritus of the Division of Medical Oncology at UCSF and served as the founding Deputy Director and Director of Research Programs at the UCSF Helen Diller Family Comprehensive Cancer Center.

The ideas and viewpoints expressed in this editorial are those of the author and do not necessarily represent any policy, position, or program of NCCN. 